\title{
Low Risk of COVID-19 Infection in an Ambulatory Gastrointestinal Endoscopy Center in Argentina
}

\author{
José Tawil, ${ }^{1 *}$ Josie Libertucci, ${ }^{2 *}$ Ana Adet Caldelari, ${ }^{3}$ Irene Banchero, ${ }^{4}$ Sandra Canseco, ${ }^{1}$ \\ Ricardo Figueredo, ${ }^{1}$ Maria Garcia, ${ }^{1}$ Cristina Machado, ${ }^{5}$ Vanesa Del Arbol, ${ }^{6}$ Christian Sánchez, ${ }^{1}$ \\ Elena F Verdu, ${ }^{2}$ Cecilio Cerisoli, ${ }^{1}$ Luis Caro $^{1}$
}

${ }^{1}$ Digestive Endoscopy Unit; Gastroenterología Diagnóstica y Terapéutica GEDyT SA, Buenos Aires, Argentina.

${ }^{2}$ Farncombe Family Digestive Health Research Institute, Department of Medicine, McMaster University, Hamilton, Ontario, Canada.

${ }^{3}$ Gastroenterology Unit; Gastroenterología Diagnóstica y Terapéutica GEDyT SA, Buenos Aires, Argentina.

${ }^{4}$ Clinical Audit:Gastroenterología Diagnóstica y Terapéutica GEDyT SA, Buenos Aires, Argentina.

${ }^{5}$ Endoscopy Assistant in Charge of Patients' Follow-up; Gastroenterología Diagnóstica y Terapéutica GEDyT SA, Buenos Aires, Argentina.

${ }^{6}$ Chief of Endoscopy Assistants, Digestive Endoscopy Unit, Gastroenterología Diagnóstica y Terapéutica GEDyT SA, Buenos Aires, Argentina.

*These authors contributed to this work as co-first authors.

Acta Gastroenterol Latinoam 2021;51(2):181-188

Received: 24/12/2020 / Accepted: 10/05/2021 / Published online: 21/06/2021 / https://doi.org/10.52787/zojk8572

\begin{abstract}
Summary
Background and Objectives. Since the onset of the COVID-19 pandemic, concerns have been raised regarding the risk of infection to both healthcare staff and patients during gastrointestinal endoscopy procedures. Given the importance of performing routine endoscopic procedures to an individual's future health, we sought to estimate the risk of COVID-19 infection for healthcare staff and patients undergoing endoscopic studies at an ambulatory endoscopy center during the pandemic. Material and Methods. This is a prospective(and) analytical cohort study conducted in an ambulatory gastroenterology center located in the Autonomous City of Buenos Aires, Argentina. Patients undergoing different endoscopic procedures were evaluated for COVID-19 between April 14 and August 31, 2020.
\end{abstract}

Correspondence: José Tawil

Virrey del Pino 2458, 4 A (C1426EBA). Buenos Aires, Argentina Email:drjosetawil@gmail.com
COVID-19 was also evaluated in all healthcare and associated staff during the same time period. The risk (cumulative incidence) of acquiring COVID-19 in all patients and staff was calculated. Results. Between April 14 and August 31, 2020, procedures were performed in 3,745 patients with a mean age of 51.12 years; $2,102(56.18 \%)$ were male and 1,643 (43.82\%) were female. Follow-up was completed in 3,492 patients, 18 of whom tested positive for COVID-19 standing for an incidence of 0.52\% (95\%CI $0.31-0.81 \%)$. Six (5.45\%) out of 110 staff members were infected with COVID-19 (1 endoscopist, 4 endoscopy assistants and 1 administrative staff member). In this group, the incidence of positive tests for COVID-19 was 5.45\% (95\%CI: $2.03-11.50 \%)$. The increased rates of positive cases among our patients and healthcare professionals were respectively 7.9 and 23.6 times lower than in general population. Conclusion. During the study period, the proportion of COVID-19 infections in our ambulatory specialized in gastrointestinal endoscopy was low and much lower than that in the general population for both patients and healthcare professionals. Endoscopic procedures undertaken at this center were low risk, likely due to strict compliance with established pandemic protocols. Future studies should compare the risk of infection in the hospital setting.

Keywords. Ambulatory center, endoscopy, risk of infection, COVID-19. 


\section{Bajo riesgo de infección por COVID-19 en un centro de endoscopía gastro- intestinal ambulatoria en la Argentina}

\section{Resumen}

Introducción y objetivo. Desde el comienzo de la pandemia de COVID-19, se han planteado preocupaciones con respecto al riesgo de infección, tanto del personal sanitario como de los pacientes, durante los procedimientos de endoscopia gastrointestinal. Dada la importancia de realizar procedimientos endoscópicos de rutina para la salud futura de una persona, buscamos estimar el riesgo de infección por COVID-19 para el personal de atención médica y para los pacientes que se someten a estudios endoscópicos en un centro de endoscopia ambulatoria, durante la pandemia. Material y métodos. Se trata de un estudio de cohorte prospectivo, analítico y que fue realizado en un centro de gastroenterología ambulatoria ubicado en la Ciudad Autónoma de Buenos Aires, Argentina. Los pacientes sometidos a diferentes procedimientos endoscópicos fueron testeados para COVID-19 entre el 14 de abril y el 31 de agosto de 2020. También se testeó para COVID-19 a todo el personal de salud y asociado durante el mismo periodo de tiempo. Se calculó el riesgo (incidencia acumulada) de adquirir COVID-19 para todos los pacientes y el personal. Resultados. Entre el 14 de abril y el 31 de agosto de 2020, se realizaron procedimientos en 3745 pacientes, con una edad promedio de 51,12 años; 2102 (56,18\%) eran hombres y 1643 $(43,82 \%)$ eran mujeres. El seguimiento se completó en 3492 pacientes, de los cuales 18 dieron positivo por COVID-19, lo que representa una incidencia del 0,52\% (IC95\% 0,31-0,81\%). Seis (5,45\%) de 110 miembros del personal estaban infectados con COVID-19 (un endoscopista, cuatro asistentes de endoscopia y un miembro del personal administrativo). En este grupo, la incidencia de pruebas positivas para COVID-19 fue del 5,45\% (IC95\%: 2,03-11,50\%). Las tasas de aumento de casos positivos entre nuestros pacientes y profesionales sanitarios fueron respectivamente 7,9 y 23,6 veces más bajas que en la población general. Conclusión. Durante el periodo de estudio, la proporción de infecciones por COVID-19 en nuestro centro ambulatorio especializado en endoscopía gastrointestinal, y bajo los protocolos recomendados por las distintas sociedades cientificas, fue baja y muy inferior a la de la población general, tanto para los pacientes como para los profesionales sanitarios. Los estudios futuros deben comparar el riesgo de infección en el ámbito hospitalario.

Palabras claves. Centro ambulatorio, endoscopia, riesgo de infección, COVID-19.

\author{
Abbreviations \\ GI: Gastrointestinal. \\ PPE: Personal protective equipment.
}

\section{Background and Objectives}

SARS-CoV-2, the virus responsible for the COVID-19 pandemic, has overwhelmed the healthcare system worldwide. In many countries, non-COVID-19 related procedures and healthcare were either reduced, halted, or limited to emergency care during the first wave of the pandemic, when many countries were on a tight lockdown in an effort to curb COVID-19 infections. The disruption of non-COVID-19 healthcare was done to free-up resources and trained personnel to help respond to the pandemic and also to limit the spread of the virus and reduce outbreaks. Elective GI procedures, including colonoscopies and endoscopies, were among the nonCOVID-19 procedures affected during the pandemic. The gastrointestinal (GI) endoscopist, anesthesiologist, endoscopy assistant, and patient come into close contact during GI procedures. Aerosolization specifically related to the GI endoscopy procedure, such as coughing and burping, ${ }^{1}$ as well as contamination by biopsy channel ${ }^{2}$ manipulation, can occur, raising concerns that performing a procedure during the COVID-19 pandemic poses a significant risk of infection to both the healthcare provider and patient. In response to these concerns, most scientific societies ${ }^{3}$ have recommended postponing elective GI procedures except in emergency situations or in patients presenting with new or severe symptoms.

Recent studies have shown that the relative risk of infection transmission during GI endoscopy procedures is relatively low. ${ }^{4,5,6} \mathrm{It}$ is unclear whether this applies to centers in developing countries, such as Argentina. Many scientific societies have made recommendations to implement additional protective measures in an attempt to prevent transmission of COVID-19 during endoscopies, ${ }^{7,8,9}$ including the use of personal protective equipment (PPE) such as respirator masks (N95, FFP2 or equivalent), surgical masks, double gloves, water-repellent gowns and coveralls, face shields and/or goggles, and waterproof boots or footwear. ${ }^{10}$ It is not yet known whether these recommendations would be easily implemented and maintained over time in all South American endoscopy units.

The pandemic continues to significantly affect many of the world's countries and, although several vaccines are now available, the percentage of the world's population vaccinated remains low. ${ }^{11}$ The reduction of GI endoscopy procedures will result in a backlog and compromise future patient care. Most importantly, delaying GI endoscopic 
procedures could lead to increased cancer rates, which have been reported in China ${ }^{12}$ and the United Kingdom ${ }^{13}$ as a direct result of postponing GI endoscopy procedures. Thus, the need to resume elective endoscopies is a current issue, as safety concerns need to be addressed, and more evidence is needed to assess the risk of infection during these types of procedures. Therefore, the purpose of this study was to evaluate the risk of COVID-19 infection for both healthcare workers and patients undergoing endoscopic procedures at a specialized ambulatory endoscopy center between April 14 and August 31, 2020 in Buenos Aires, Argentina.

\section{Material and Methods}

\section{Overall Design}

This was a prospective and analytical, cohort study conducted in an ambulatory gastroenterology center located in the Autonomous City of Buenos Aires, Argentina. Patients undergoing different endoscopic procedures were evaluated between April 14 and August 31, 2020. The last patient was included on August 16 and the study ended on August 31. The center has 8 endoscopy rooms and 6 recovery rooms. Only 5 of all endoscopy rooms have been used since reopening.

\section{Healthcare Staff Included in this Study}

All physicians (endoscopists and anesthesiologists), endoscopy assistants, administrative staff and cleaning staff working in the center were included in the study period. All personnel worked an average of 30 hours per week.

\section{Patients Included in this Study}

Consecutive patients aged 18 to 79 years who came to the center for elective endoscopy were asked to sign an informed consent form and to complete a sworn statement declaring they had tested negative for COVID-19 before the study was performed. Patients with a history of cardiovascular, renal and/or neurological disease, type 1 diabetes and those older than 65 years underwent a cardiovascular risk assessment to ensure the safety of the procedure in an ambulatory center. Patients aged $<18$ and $>80$ years, those at risk of acquiring COVID-19, with temperatures above $37.5^{\circ} \mathrm{C}$ prior to the study and/ or who refused to sign the informed consent and sworn statement were excluded.

\section{Establishment of COVID-19 Protocol for GI Endos- copy Procedures}

The day before the procedure, patients were contacted by telephone by previously trained administrative staff to ensure the absence of COVID-positive tests and symptoms compatible with the infection, including fever, sore throat, myalgias, loss of smell, etc. On the day of the procedure, the temperature was taken to both the patient and the patient's companion, all of them received a surgical mask, and were asked to sanitize their hands. After admission, the patient entered the restricted area accompanied by a healthcare worker wearing full PPE, which included respiratory masks (N95), double gloves, water-repellent gowns and coveralls, face shields and/or goggles, and waterproof boots or footwear. Once in a separate private room, the patient donned a disposable surgical gown without removing their mask and was taken to the endoscopy room on a gurney. The personal protective equipment was used by the medical staff, operating room assistants, and the cleaning and administrative staff complied with the PPE recommended by the endoscopy societies. ${ }^{6,7,10}$ The medical staff (endoscopist, anesthesiologist and operating room assistants) had a special room in which gloves, surgical gown, masks and boots were stored and in which they put on the PPE, before seeing the patient.

\section{Endoscopic Procedures}

Upper GI endoscopy, colonoscopy, and endoscopic ultrasound were performed under propofol sedation and cardiac monitoring by the anesthesiologist, under stringent protocol-compliance, ${ }^{6,7}$ and with each team member wearing PPE.

Between April 14 and August 31, 2020, a total of 3,745 procedures were performed, of which 855 were upper GI endoscopies, 1,140 colonoscopies, 1,611 combined procedures (video colonoscopy and upper gastrointestinal endoscopy), 9 recto sigmoidoscopies and 130 endoscopic ultrasounds (GI, biliary tract and rectal). During the same period in 2019, a total of 15,984 procedures were performed, representing a $76.5 \%$ reduction during COVID-19 pandemic. Similar differences when compared to the number of studies in 2018 (15,724).

\section{Telephone Interviews}

Once the endoscopy was completed and the patient was discharged, on days 1,7 , and 14 post procedure, a trained staff member contacted the patient by telephone. The patient was asked if they or the support person had any COVID-19 symptoms. If the answer was yes, a viral PCR swab test was performed.

\section{Statistical Analysis}

Data were entered in an Excel-type database and analyzed using the statistical packages SPSS 16 from SPSS 
INC (1989-2007) and MedCalc 11.2 from MedCalc Software (1993-2010). Frequency distributions and appropriate descriptive statistics were determined for each variable, according to their measurement scales. When necessary, the following estimates were calculated: $95 \%$ confidence interval; incidence or absolute risk and Chisquare goodness-of-fit test. Results were expressed to 1 or 2 decimals according their clinical relevance. The significance level was set at 0.05 . Baseline and situational conditions in terms of COVID-19 exposure were different for the patient population and the healthcare team, as the latter is exposed every time a procedure is performed.

\section{Ethical Responsibilities and Data Confidentiality Statement}

No human or animal experiments were performed during this research. The data of included and excluded patients have been preserved. The research protocol was previously accepted by the Education and Research Committee (CODEI) and the GEDyT Ethics Committee.

\section{Results}

\section{Description of the Sample of Healthcare and Sup- port Staff}

A total number of 110 healthcare and support staff members were enrolled in this study (Table 1). Three of the 35 medical endoscopists, enrolled in this study, performed on-call emergency procedures at medical centers other than the center included in this study. Of the 25 medical anesthesiologists, 6 worked in other clinics and hospitals outside the center included in this study. Of a total number of 35 endoscopy unit assistants, 11 participated in emergency endoscopies in other clinics and 2 worked simultaneously in hospitals.

Table 1. Characteristics of Healthcare and Support Staff Involved in this Study

\begin{tabular}{|c|c|c|c|}
\hline Healthcare Team & $\mathrm{N}$ & Sex, Female: n (\%) & Years Old: Mean (SD) \\
\hline Medical Endoscopists & 35 & $15(42.9)$ & $45(8.78)$ \\
\hline Medical Anesthesiologists & 25 & $6(24.0)$ & $48(10.45)$ \\
\hline Endoscopy Assistants & 35 & $32(91.4)$ & $34(5.42)$ \\
\hline Cleaning Staff & 8 & $5(62.5)$ & $40(11.77)$ \\
\hline Administrative Staff & 7 & $7(100.0)$ & $30(3.98)$ \\
\hline Overall & 110 & $65(59.1)$ & $41(10.29)$ \\
\hline
\end{tabular}

\section{COVID-19 Infection Rates in Healthcare and Support Staff}

The cumulative incidence of COVID-19 infection is shown in Table 2.

Two physician anesthesiologists had symptoms compatible with COVID-19 but, tested negative. Only one physician endoscopist out of the 35 enrolled in this study tested positive for COVID-19. Four of the 35 endoscopy assistants had symptoms and tested positive. None of the cleaning staff had symptoms or tested positive, and only 1 of the 7 administrative staff had symptoms and tested positive (Table 2).
The incidence of COVID-19 positive cases during the study period and for all healthcare and support staff was confirmed to be $5.45 \%$. The breakdown by workplace revealed that endoscopy assistants (11.43\%) appeared to be the most affected, with no cases among anesthesiologists and cleaning staff. The chi-square goodness-of-fit test for incidence, according to healthcare staff groups, showed non-statistically significant differences $\left(\mathrm{chi}^{2}=5.84 ; p=0.211\right)$, which supports the hypothesis that workplace of healthcare staff is unrelated to the risk of acquiring COVID-19 (Table 2). 
Table 2. Cumulative Incidence Rates of COVID-19 Infection within Healthcare Staff

Incidence Rate COVID +

95\% Confidence Interval

$\begin{array}{lllll}\mathrm{N} & \mathrm{COVID}+ & \% & \mathrm{LL} & \mathrm{UL}\end{array}$

\begin{tabular}{|c|c|c|c|c|c|}
\hline Medical Endoscopists & 35 & 1 & 2.86 & 0.07 & 14.92 \\
\hline Medical Anesthesiologists & 25 & 0 & 0.00 & 0.00 & 13.23 \\
\hline Endoscopy Assistants & 35 & 4 & 11.43 & 3.20 & 26.74 \\
\hline Cleaning Staff & 8 & 0 & 0.00 & 0.00 & 36.94 \\
\hline Administrative Staff & 7 & 1 & 14.29 & 0.36 & 57.87 \\
\hline Overall & 110 & 6 & 5.45 & 2.03 & 11.50 \\
\hline
\end{tabular}

LL: lower limit; UL: upper limit.

\section{COVID-19 Infection Rates in Patients}

A total number of 3,745 patients (mean age/SD; $51 \pm 14)$ were enrolled in this study $(2,102$ or $56.18 \%$ were male and 1,643 or $43.82 \%$ were female). Of the 3,745 patients, follow-up telephone calls on day 1,7 and 14 were completed in 3,492 (93.2\%) patients and $253(6.8 \%)$ were lost during the follow-up period. Of the $3,492$ patients, 18 (0.52\%, IC 95\% $0.31-0.81 \%)$ had symptoms associated with COVID-19 within 14 days of the procedure (Table 3 ).

Table 3. Cumulative Incidence Rates of COVID-19 in Patients

COVID + Incidence Rate

95\% Confidence Interval

N

3492

3487

3492
COVID +

5

13

18
0.14

0.37

0.52
LL

0.05

0.20

0.31
UL

0.81 
All 18 patients were tested for COVID-19 by nasal swabbing and tested positive. Of those who tested positive, the mean age/SD was $47 \pm 14$ and $13(72.2 \%)$ were female.

Only $5(27.7 \%)$ of the 18 COVID-19 positive patients acquired the disease within the first 7 days and $13(73.3 \%)$ between day 7 and 14 . It was observed that, in this protocol-compliant patient population, the incidence of procedure-related infection reached an upper limit of $0.33 \%$ at day 7 and $0.64 \%$ at day 14 with a 95\% confidence interval.

\section{Discussion}

COVID-19 was first identified in China, then spread to Europe and has since affected all the Americas, in particular the United States, Ecuador, Brazil, Chile and Argentina. ${ }^{14}$ By mid-March 2020, Argentina had 128 cases reported and 3 deaths associated with COVID-19, and, on March 19, the country entered a strict lockdown imposed by the Argentine Ministry of Health until April $13^{\text {th }} .{ }^{15}$ During this time, only healthcare and security personnel were allowed to leave their homes. From April 13 and progressively thereafter, the country began to reopen different areas, but it was not until August when most activities were resumed. At the end of August, when this study was completed, there were 417,735 COVID-19 infections and 8,660 deaths, ${ }^{16}$ most cases occurring in Buenos Aires.

Although limited, Argentina has a universal staterun healthcare system, but a considerable number of hospitals lack high complexity services. Argentina's healthcare system is made up of three sectors: public, social security, and private. The public sector consists of national and provincial ministries, and the network of public hospitals and health centers that provide free care to anyone who demands it, mainly to people without social security and unable to afford the cost. The public health system is financed with fiscal resources and receives timely payments from the social security system when it attends its affiliates. The social security sector is organized around labor unions, which insures and provides services to workers and their families. Most labor unions operate through contracts with private providers and are financed with contributions from workers and employers. The private sector is made up of healthcare professionals and facilities that serve individual claimants, beneficiaries of labor unions and private insurance. This sector also includes voluntary insurance entities called prepaid medicine companies that are mainly financed by premiums paid by families and/or companies. Our ambulatory endoscopic center provides endo- scopic studies not only for private patients but also for patients with prepaid insurance. ${ }^{16}$

For this reason, approximately $50 \%$ of the population that can afford private care chooses between union-run healthcare or private insurance in order to access better-equipped medical care. ${ }^{17}$ In the context of private care in Argentina, many endoscopy centers are located within hospitals (private or state-run). Hospitals are considered high-risk environments conducive to transmission of infections and, in order not to overload the healthcare system, only emergency procedures were performed. Routine screening and monitoring procedures for lesions previously diagnosed and scheduled for resection were cancelled at the time of the pandemic outbreak and remain unscheduled in the hospital setting. Thus the continuation of procedures in specialized private endoscopic clinics, such as the one used in this study, which can maintain safety measures, may offload patients from the large hospitals that would suffer the greatest number of COVID-19 cases. At the same time, preventive diagnosis of treatable lesions is continued.

Since the onset of the COVID-19 pandemic, most countries report a significant decline in elective GI procedures. Within the United Kingdom, an 88\% decrease was reported in April and May 2020.12 Our study is indicating a $76 \%$ decrease from April to August compared to 2019 and 2018. The reduction in elective GI procedures could have serious side effects for many patients. Indeed, a study performed in Hong Kong estimated that the 6-month delay in performing diagnostic endoscopy, due to the COVID-19 pandemic, correlates with an increase in advanced cancer stages for both GI and colorectal cancer. Endoscopy procedures were reduced by more than $50 \%$ which has subsequently led to a decrease in patients diagnosed with gastric and colorectal cancer by $49.1 \%$ and $38.1 \%$, respectively, compared to the last three years. ${ }^{13}$ In Buenos Aires, the decision to cancel non-urgent endoscopic procedures due to the potential risk of infection was shared by medical societies, healthcare professionals and patients. Although the impact has not yet been measured, there is a growing number of patients with advanced stage lesions who have delayed their visits for fear of attending a healthcare center or because their trusted physician was not available.

Studies from China ${ }^{17}$ and Italy ${ }^{18}$ have shown that healthcare personnel have a higher risk of COVID-19 infection compared with the general population; however, so far, studies from the United Kingdom ${ }^{6}$ and two case series from Italy ${ }^{4,5}$ show a low probability of infection among healthcare personnel and patients relative to endoscopic procedures. An international sur- 
vey of 252 endoscopic centers from 55 different countries across 6 continents also reported a low proportion of COVID-19 among the endoscopy staff, suggesting that the risk of transmission of this infection among endoscopy staff while using appropriate PPE may be low. ${ }^{19}$ Our study supports these findings, as the number of patients and healthcare personnel who contracted COVID-19 was low. The low infection rates are most likely contributed to the implementation of screening patients prior to their appointments, double gloves, N95 respiratory masks and endoscopy room disinfection. All of these have shown to be effective in protecting healthcare personnel, both in this study and others. ${ }^{20,21}$

Our study revealed that of the 3,492 patients followed and of the 110 healthcare workers who participated in endoscopic procedures during the study period only $0.51 \%$ and $5.40 \%$, respectively, were infected with COVID-19.

Only $5(27.7 \%)$ of the 18 infected patients presented symptoms and tested positive within the first 7 days. It should be clarified that during the 14-day period following the endoscopic procedure the patients resumed their usual activities, which means the patient could have increased their risk of infection from other potential sources and a positive COVID-19 result might not necessarily come from the clinic.

Most of the COVID-19 cases occurred concurrently with the growing number of cases in the general population; between March and August the country had approximately 142 -fold more cases while our center had 18-fold more infected patients and 6-fold more infected healthcare workers (throughout the study period).

Therefore, for the purpose of this study, rates of increase in positive cases among our patients and healthcare professionals were respectively 7.9 (18 vs 142) and 23.6fold (6 vs 142) lower than in general population.

It must be considered that baseline and situational conditions are different for the patient population in relation to the healthcare team. The number of times each patient has been exposed to the infection is unknown. Conversely, healthcare workers are exposed every time an endoscopic procedure begins and thus, the risk should be higher. The results of this follow-up suggest that the risk of infection is very low and should be weighed against the risk of delaying the endoscopic diagnosis of serious conditions.

Our study has some limitations, firstly, the protocol did not include swab testing of healthcare staff and patients before endoscopy or during follow-up of patients after the procedure. Only those who had symptoms or were in close contact with a COVID-positive person were tested, as indicated by the protocol of the Argentine
Ministry of Health ${ }^{22}$ and the recommendations of the Endoscopy Society of Buenos Aires. ${ }^{23}$ Secondly, we did not compare the risk of infection in our center (private and ambulatory) versus the risk in clinics and hospitals, because endoscopic procedures in these medical centers were limited to emergencies.

\section{Conclusion}

During the study period, the proportion of COVID-19 infections in our specialized gastrointestinal endoscopy ambulatory center was low and much lower than that of the general population, both for patients and professionals. We can conclude that, if established protocols for endoscopic procedures are strictly adhered to, the risk of infection in specialized endoscopic clinics is low. This provides a setting to offload the burden to larger hospitals, as well as to continue preventative screenings during COVID-19 pandemic. Further studies should be conducted to compare with infection rates during endoscopy performed in larger hospitals.

Acknowledgements. This project was supported by the Gastroenterología Diagnóstica y Terapéutica (GEDyT SA), an ambulatory gastrointestinal endoscopy center in Buenos Aires, Argentina. JL holds an IMAGINE-CIHR-CAG fellowship. EFV holds a Canada Research Chair.

Conflict of interest. There is no conflict of interest to declare.

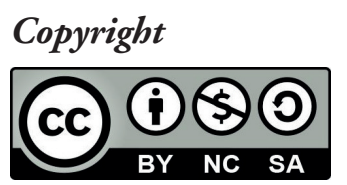

(C) 2021 Acta Gastroenterológica latinoamericana. This is an openaccess article released under the terms of the Creative Commons Attribution (CC BY-NC$S A$ 4.0) license, which allows non-commercial use, distribution, and reproduction, provided the original author and source are acknowledged.

Cite this article as: Tawil J, Libertucci J, Caldelari AA, et al. Low Risk of COVID-19 Infection in an Ambulatory Gastrointestinal Endoscopy Center in Argentina. Acta Gastroenterol Latinoam. 2021;51(2):181-8. https://doi. org/10.52787/zojk8572

\section{References}

1. Ong SWX, Tan YK, Chia PY, et al. Air, surface environmental, and personal protective equipment contamination by severe acute respiratory syndrome coronavirus 2 (SARS-CoV-2) from a symptomatic patient. JAMA. Epub, 2020. 
2. Vavricka S, Tutuian R, Imhof A. Air suctioning during colon biopsy forceps removal reduces bacterial air contamination in the endoscopy suite. Endoscopy. 2010;42:736-41.

3. Repici A, Aragona G, Cengia G, et al. Low risk of COVID-19 transmission in GI endoscopy. Gut. 2020;0:1-3.

4. Repici A, Pace F, Gabbiadini R, et al. Endoscopy Units and the Coronavirus Disease 2019 Outbreak: A Multicenter Experience from Italy. Gastroenterology 2020;159:363-6.

5. Hayee B, Thoufeeq M, Rees CJ, et al. Safely restarting GI endoscopy in the era of COVID-19. Gut. 2020.

6. Soetikno R, Teoh AYB, Kaltenbach T, et al. Considerations in performing endoscopy during the COVID-19 pandemic. Gastrointest Endosc. 2020;92(1):176-83.

7. Sultan S, Lim JK, Altayar O, et al. AGA Institute Rapid Recommendations for Gastrointestinal Procedures During the COVID-19 Pandemic. Gastroenterology 2020;159:739-58.

8. WorldHealthOrganization. Rationaluseofpersonal protectiveequipmentfor coronavirus disease(COVID-19): interim guidance, 27 February 2020. Geneva: World Health Organization; 2020. Available at: https:/extranet.who.int/iris/restricted/handle/10665/331215 Accessed March 18, 2020.

9. Organization WH. Rational use of personal protective equipment for coronavirus disease (COVID-19): interim guidance, Geneva. 2020.

10. Ortega R, Bhadelia N, Obanor O, et al. Putting on and removing personal protective equipment. N Engl J Med. 2015;372:e16.

11. Vacunas contra el coronavirus: Cual es la situación en tu país?. Disponible en: https://www.bbc.com/mundo/noticias-56025727

12. Rutter MD, Brookes M, Lee TJ, et al. Impact of the COVID-19 pandemic on UK endoscopic activity and cancer detection: a National Endoscopy Database Analysis. Gut. 2020; published online July 19. Available at: https://doi:10.1136/gutjnl-2020-322179

13. Lui TKL, Leung K, Guo C-G, et al. Impacts of COVID-19 pandemic on gastrointestinal endoscopy volume and diagnosis of gastric and colorectal cancers: a population-based study. Gastroenterology. 2020; published online May 17. Available at: https://doi.org/10.1053/j.gastro.2020.05.037
14. Gutierrez P. Coronavirus world map which countries have the most cases and deaths. Coronavirus updates. April 5-2020, 11.25 UTC. In: The Guardian. 2020; ed. Volume 2020.

15. Información epidemiológica COVID-19. Ministerio de Salud de la Nación. Disponible en: https://www.argentina.gob.ar/salud/ coronavirus-COVID-19/sala-situacion

16. Dirección general de Estadísticas y Censos, Ministerio de Hacienda- Disponible en: https://www.estadisticaciudad.gob.ar/si/genero/principal-indicador?indicador=tip_cob_sal

17. Report of the WHO-China Joint Mission on Coronavirus Disease 2019 (COVID-19), February 16-24, 2020. Available at: https://www.who.int/docs/default-source/coronaviruse/who-chinajoint-mission-on-covid-19-finalreport.pdf

Accessed March 27, 2020.

18. Remuzzi A, Remuzzi G. COVID-19 and Italy: what next? Lancet. 2020;395(10231):1225-8.

19. Parasa S, Reddy N, Faigel DO, et al. Global Impact of the COVID-19 Pandemic on Endoscopy: An International Survey of 252 Centers From 55 Countries. Gastroenterology. 2020;159:1579-81.

20. Offeddu V, Yung CF, Low MSF, et al. Effectiveness of masks and respirators against respiratory infections in healthcare workers: a systematic review and metanalysis. Clin Infect Dis. 2017;65:1934-42.

21. Tran K, Cimon K, Severn M, et al. Aerosol generating procedures and risk of transmission of acute respiratory infections to healthcare workers: a systematic review. PLoS One. 2012;7:e35797.

22. Protocolo de manejo frente a casos confirmados de COVID-19. Ministerio de Salud de la Nación. Disponible en: https://www.argentina.gob.ar/salud/coronavirus-COVID-19

23. Recomendaciones para unidades de endoscopia. Comité de revisión ENDIBA-COVID-19. Disponible en: https://endiba.org. ar/recomendaciones_unidades_endoscopia_IV.pdf 